\title{
A retrospective comparative study of postoperative sagittal balance in isthmic L5-S1 spondylolisthesis using single segment or two-segment pedicle screw fixation
}

\author{
Xiaofeng Shao ${ }^{1 \dagger}$, Hao Liu ${ }^{1 \dagger}$, Jian Wu ${ }^{2+}$, Zhonglai Qian ${ }^{1 *}$, Rui Qu$^{3^{*}}$ and Tao Liu ${ }^{{ }^{*}}$
}

\begin{abstract}
Objective: To compare the radiographic parameters and clinical outcomes of isthmic L5-S1 spondylolisthesis with single segment or two-segment pedicle screw fixation.

Methods: Between January 2018 and January 2019, a total of 76 patients with isthmic L5-S1 spondylolisthesis were included in this study. All patients were treated with varying numbers of pedicle screw fixation with single-segment fusion during posterior lumbar interbody fusion (PLIF). Patients were divided into two groups, based on the number of pedicle screws placed during fixation, namely, 4 screws (4S) group and 6 screws (6S) group. Subsequently, the sagittal balance parameters were measured, which included slippage degree (SD), lumbar lordosis (LL), segmental lordosis (SL), pelvic incidence (PI), pelvic tilt (PT), sacral slope (SS), and sagittal vertical axis (SVA). Clinical functional outcomes were assessed using the visual analog scale (VAS) for back pain and the oswestry disability index (ODI) scores.

Results: The $4 S$ group comprised of 10 males and 27 females, with a median age of $55.2 \pm 10.8$ years old and a mean follow-up of $16.95 \pm 4.16$ months. The $6 \mathrm{~S}$ group comprised of 14 males and 25 females, with a median age of $58.1 \pm 7.5$ years old and a median follow-up of $17.33 \pm 3.81$ months. No significant differences were evident in all preoperative parameters between both groups. In contrast, the postoperative LL, SL, PT, SS, and SD values increased significantly, compared to the preoperative values in both groups (all $P<0.05$ ). At the last follow-up, the $6 \mathrm{~S}$ group exhibited better correction in LL, $S L$, and PT, relative to the $4 S$ group (all $P<0.05$ ). A significant SD difference was observed between both groups at all points post surgery $(P<0.05)$. The postoperative slip correction rate was significantly larger in the $6 \mathrm{~S}$ group, compared to the $4 \mathrm{~S}$ group $(P<0.05)$. The postoperative VAS and ODI scores of both groups improved significantly, when compared to the preoperative scores (both $P<0.05$ ). However, there were no significant differences in the ODI and VAS scores between the two groups at all time points.
\end{abstract}

\footnotetext{
*Correspondence: qzldoctor@163.com; tianrui62082@163.com; liutaodoctor@163.com

${ }^{\dagger}$ Xiaofeng Shao, Hao Liu and Jian Wu contributed equally to this work.

${ }^{1}$ Department of Orthopedic Surgery, The First Affiliated Hospital

of Soochow University, No. 188 Shizi Street, Suzhou, Jiangsu 215006, P.R.

China

${ }^{3}$ Department of Orthopedic Surgery, The Affiliated Suzhou Hospital

of Nanjing Medical University, No. 26 Daoqian Street, Suzhou, Jiangsu

215006, P.R. China

Full list of author information is available at the end of the article
}

(c) The Author(s) 2022. Open Access This article is licensed under a Creative Commons Attribution 4.0 International License, which permits use, sharing, adaptation, distribution and reproduction in any medium or format, as long as you give appropriate credit to the original author(s) and the source, provide a link to the Creative Commons licence, and indicate if changes were made. The images or other third party material in this article are included in the article's Creative Commons licence, unless indicated otherwise in a credit line to the material. If material is not included in the article's Creative Commons licence and your intended use is not permitted by statutory regulation or exceeds the permitted use, you will need to obtain permission directly from the copyright holder. To view a copy of this licence, visit http://creativecommons.org/licenses/by/4.0/. The Creative Commons Public Domain Dedication waiver (http://creativeco $\mathrm{mmons.org/publicdomain/zero/1.0/)} \mathrm{applies} \mathrm{to} \mathrm{the} \mathrm{data} \mathrm{made} \mathrm{available} \mathrm{in} \mathrm{this} \mathrm{article,} \mathrm{unless} \mathrm{otherwise} \mathrm{stated} \mathrm{in} \mathrm{a} \mathrm{credit} \mathrm{line} \mathrm{to} \mathrm{the} \mathrm{data.}$ 
Conclusions: The clinical outcomes of both approaches appeared to be satisfactory. In terms of short-term outcomes, the $6 \mathrm{~S}$ group exhibited better spinal sagittal restoration and stability than the $4 \mathrm{~S}$ group.

Keywords: Lumbar spondylolisthesis, Sagittal balance, Lumbar pedicle screw fixation

\section{Introduction}

Isthmic spondylolisthesis is a common spinal disease that results from a pars interarticular defect and the L5-S1 region is the most commonly affected region. Lumbar spondylolisthesis manifestations are related to lumbar spinal stenosis, which produces symptomatic compression of the neural element. However, it can also surface due to segmental instability. This condition is initially treated with conservative management strategies. But, in case a patient fails to respond, surgery is recommended. Surgical intervention can effectively relieve dural sac and nerve root compression, prevent spondylolisthesis degeneration from aggravation, correct spinal deformity, and stabilize the lumbar spine [1]. Posterior lumbar interbody fusion (PLIF) is a widely used surgical approach for treating lumbar spondylolisthesis. Moreover, pedicle screw placement is crucial to the success of PLIF-based fusion, and has shown remarkable clinical outcomes $[2,3]$.

In recent years, spinopelvic sagittal balance is widely recognized as a crucial factor regulating clinical outcomes in patients undergoing spinal surgery [4]. Since lumbar spondylolisthesis often combines with other deformities like forward slip and kyphosis, it often results in a global sagittal imbalance of the spine. Spinopelvic sagittal balance is essential in the evaluation and treatment of patients with spondylolisthesis. Traditionally, fixation placement involves inserting two pedicle screws in the slipped and lower vertebral bodies, in an approach known as short segment fixation. In our study, additional pedicle screws were implanted into the upper vertebrae of the slipped vertebrae, thereby making it a long segment fixation. Till date, limited studies reported on the influence of short versus long segment pedicle screw fixation on sagittal balance in lumbar spondylolisthesis. Given its significance in determining surgical success, it is essential to examine the outcomes of inserting varying number of screws on sagittal balance in patients with lumbar spondylolisthesis.

In this retrospective study, we compared the clinical functional outcomes and sagittal balance parameters of patients with isthmic spondylolisthesis treated with varying number of screw implants during PLIF surgery.

\section{Materials and methods Patient population}

Between January 2018 and January 2019, 76 patients with L5-S1 isthmic spondylolisthesis, who underwent PLIF surgery, were selected for this study. The patients were divided into two groups, based on the surgical methods: Four screws group ( $4 \mathrm{~S}$ group): 37 patients received a single fixation with four pedicle screws. Six screws group (6S group): 39 patients received a single fixation with six pedicle screws. We obtained ethical approval from the Medical Ethics Committee of the First Affiliated Hospital of Soochow University prior to the initiation of this study.

\section{Inclusion and exclusion criteria}

The inclusion criteria were as follows: (1) patients with L5-S1 isthmic spondylolisthesis; (2) patients experiencing symptoms of unilateral/double sciatica or intermittent claudication, with low back pain, who are unresponsive to conservative therapy for over 6 months; (3) patients treated with varying numbers of pedicle screws during the L5-S1 fusion PLIF surgery; (4) Patient followup duration of more than 1 year. The exclusion criteria were as follows: (1) intervertebral space infection, spinal tumors, congenital spinal deformity, and acute vertebral fractures; (2) patients with no valid follow-up information.

\section{Surgical procedure}

All surgeries were conducted by the same two highly experienced orthopedic surgeons in order to minimize influence of varying surgical techniques. A posterior median incision was made to expose the spinous process.

In the $4 \mathrm{~S}$ group, the L5 vertebra was conventionally implanted with two pedicle screws, and two additional pedicle screws were inserted into the $\mathrm{S} 1$ vertebra, all under the guidance of C-arm X-ray fluoroscopy (Fig. 1). Next, we performed bilateral laminotomies and thorough discectomy prior to the placement of a properly sized cage, packed with laminectomy bone. Upon completion of lifting and reduction, titanium rods were placed and the nut was locked. The PLIF was limited to L5-S1.

In the $6 \mathrm{~S}$ group, the L5 vertebra was conventionally implanted with two pedicle screws, the S1 vertebra was fixed with two pedicle screws, and the L4 vertebra was implanted with two additional pedicle screws (Fig. 2). The incision and surgical procedure of the laminectomy and associated decompression followed the same protocol as the $4 \mathrm{~S}$ group. Using the cranial and caudal vertebral bodies of the slipped vertebra as anchors and a middle screw as the leverage point, we performed middle 


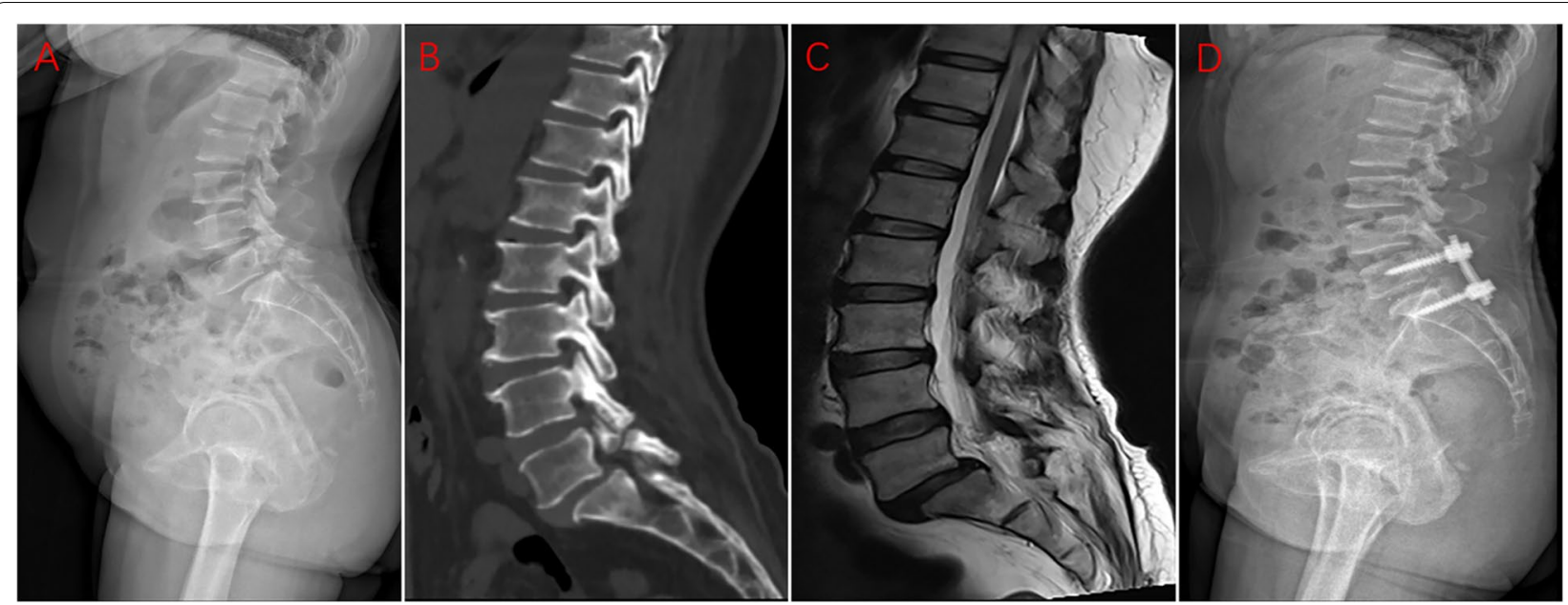

Fig. 1 The preoperative lateral X-ray image (a), preoperative sagittal CT image (b), preoperative sagittal MRI image (c), and postoperative (d) lateral X-ray image of a 60-year-old female patient, who underwent L5-S1 PLIF, with 4 screws to correct lumbar spondylolisthesis

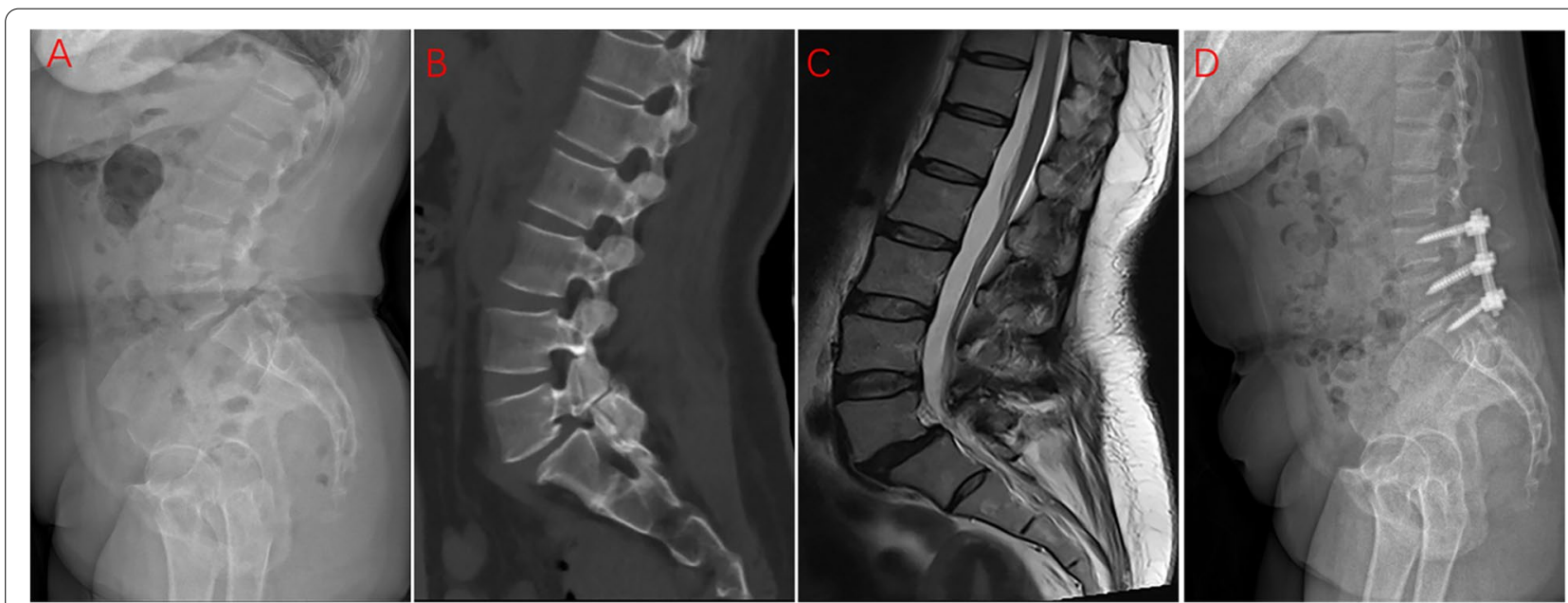

Fig. 2 The preoperative lateral X-ray image $(\mathbf{a})$, preoperative sagittal CT image $(\mathbf{b})$, preoperative sagittal MRI image $(\mathbf{c})$, and postoperative $(\mathbf{d})$ lateral X-ray image of a 63-year-old female patient, who underwent L5-S1 PLIF, with 6 screws to correct lumbar spondylolisthesis

bridge-shaped pulling reduction. Finally, the titanium rods were placed and the nut was locked. The intervertebral fusion was limited to L5-S1 and the posterior fixation was limited to L4-S1.

\section{Radiographic parameters}

Alterations in lumbar lordosis (LL), slippage degree (SD), segmental lordosis (SL), pelvic incidence (PI), sacral slope (SS), pelvic tilt (PT), and sagittal vertical axis (SVA) were assessed by the EOS system. Two observations were made, at least two weeks apart, by two independent spinal surgeons, and the mean radiological spinopelvic parameter values were used in subsequent analysis.
LL was defined as the angle between the upper endplate of the L1 and S1 (Fig. 3). PI was the angle between the line perpendicular to the midpoint of the S1 upper endplate and the line connecting the midpoint of S1 upper endplate to the bicoxo-femoral axis. PT was the angle between the vertical line and the line connecting the midpoint of the S1 upper endplate to the bicoxo-femoral axis. SS was the angle between the horizontal line and the upper endplate of S1. SL was the angle between the upper endplate of L5 and the lower endplate of the S1 vertebra. SD was assessed by the Meyerding grade (Fig. 4). The slip correction rate was calculated as follows: [(preoperative slip 


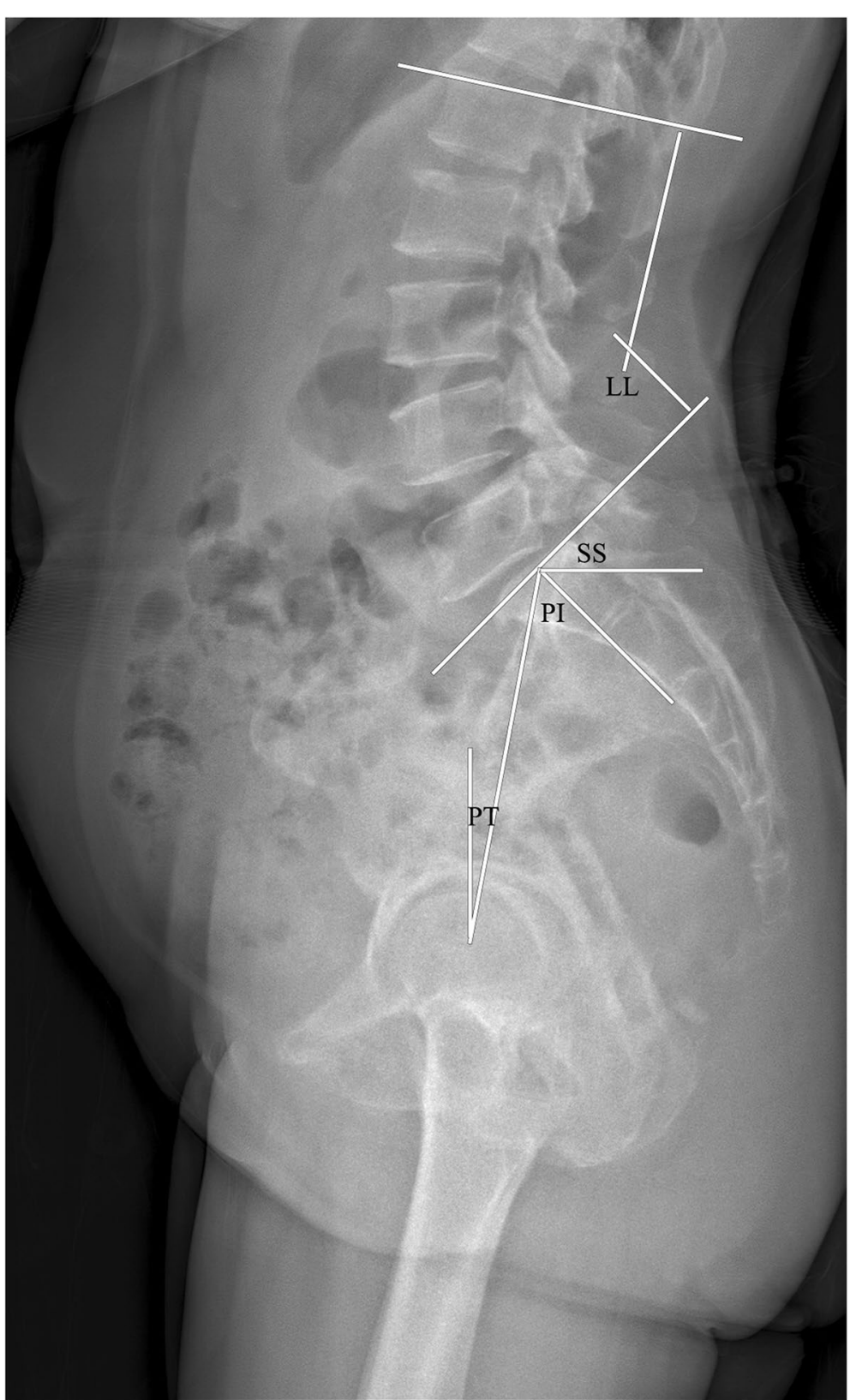

Fig. 3 The radiological parameter measurements (LL, PI, PT, and SS)

percentage - postoperative slip percentage) / (preoperative slip percentage) $] \times 100$. SVA was the distance between the posterosuperior corner of $\mathrm{S} 1$ and the $\mathrm{C} 7$ plumb line (Fig. 5).

\section{Clinical outcomes}

The visual analog scale (VAS) score was used to assess back pain in patients; lower scores indicated less pain. The oswestry disability index (ODI) was employed to evaluate quality of patient life; a higher score indicated worsening quality of life.

\section{Statistical analysis}

The SPSS 19.0 software (IBM, Armonk, NY, USA) was used for all data analyses. Data are presented as mean \pm standard. The student's $t$ test was used for numerical data, including, age, BMI, BMD, radiographic parameters, VAS scores, and ODI in both groups. The 


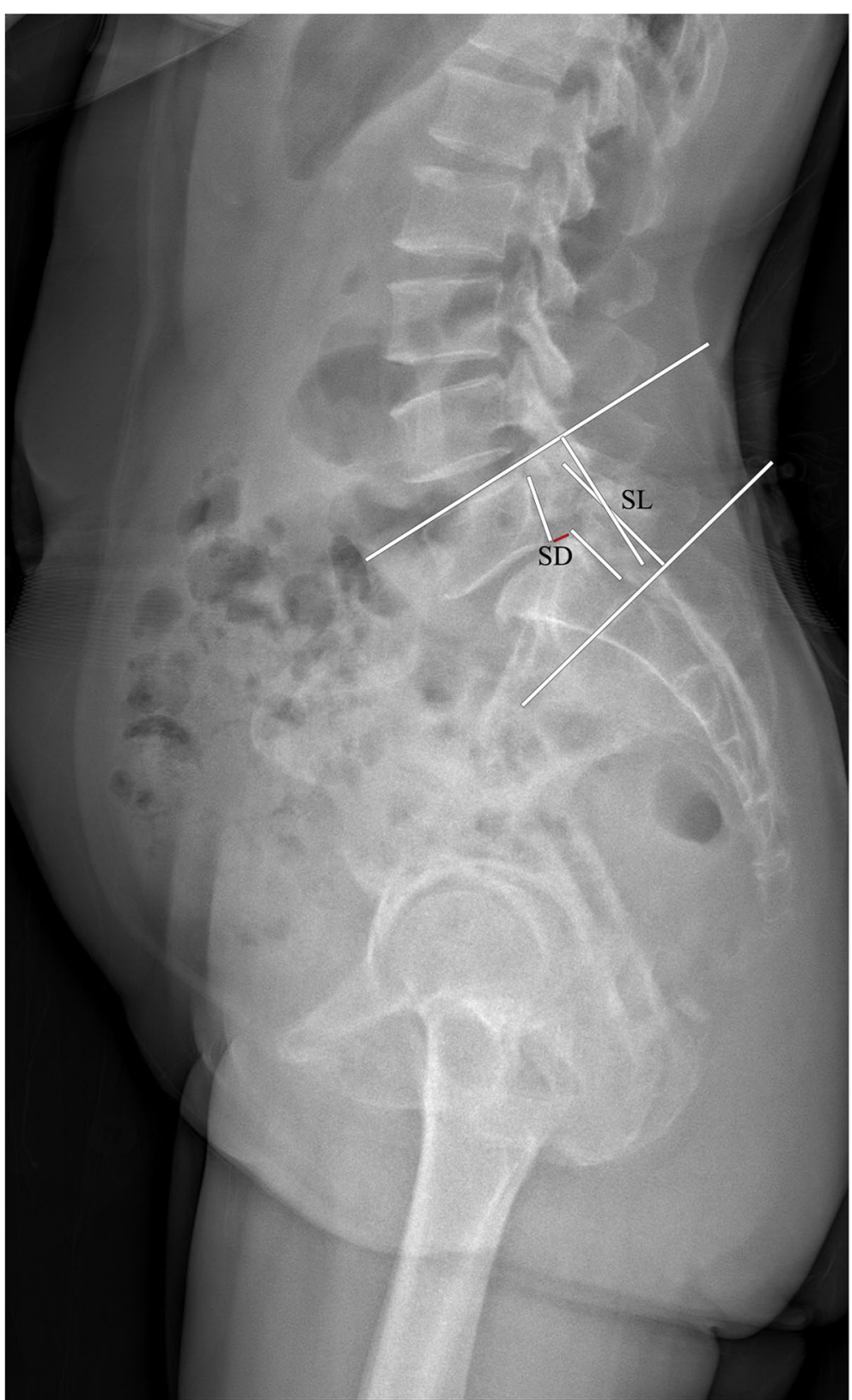

Fig. 4 The radiological parameter measurements (SD and LL)

Pearson's Chi-square and Fisher exact tests were used to analyze categorical data, including, gender and slip grade. A $p$ value less than 0.05 was considered statistically significant.

\section{Results}

\section{Demographic}

The $4 \mathrm{~S}$ group consisted of 10 males and 27 females, with a mean age of $55.2 \pm 10.8$ years old. All 37 adult patients underwent a single-segment fusion with 4 screw fixations ( $4 \mathrm{~S}$ group) and a median follow-up of $16.95 \pm 4.16$ months. The $6 \mathrm{~S}$ group consisted of 14 males and 25 females, with a median age of $58.1 \pm 7.5$ years old. No significant differences were observed in gender, age, BMI, BMD, slip grade, and preoperative SVA. The basic patient characteristics are presented in Table 1.

\section{Radiological outcomes}

The LL, SL, PT, SS, and SD increased significantly after surgery, relative to before surgery in both groups (all 


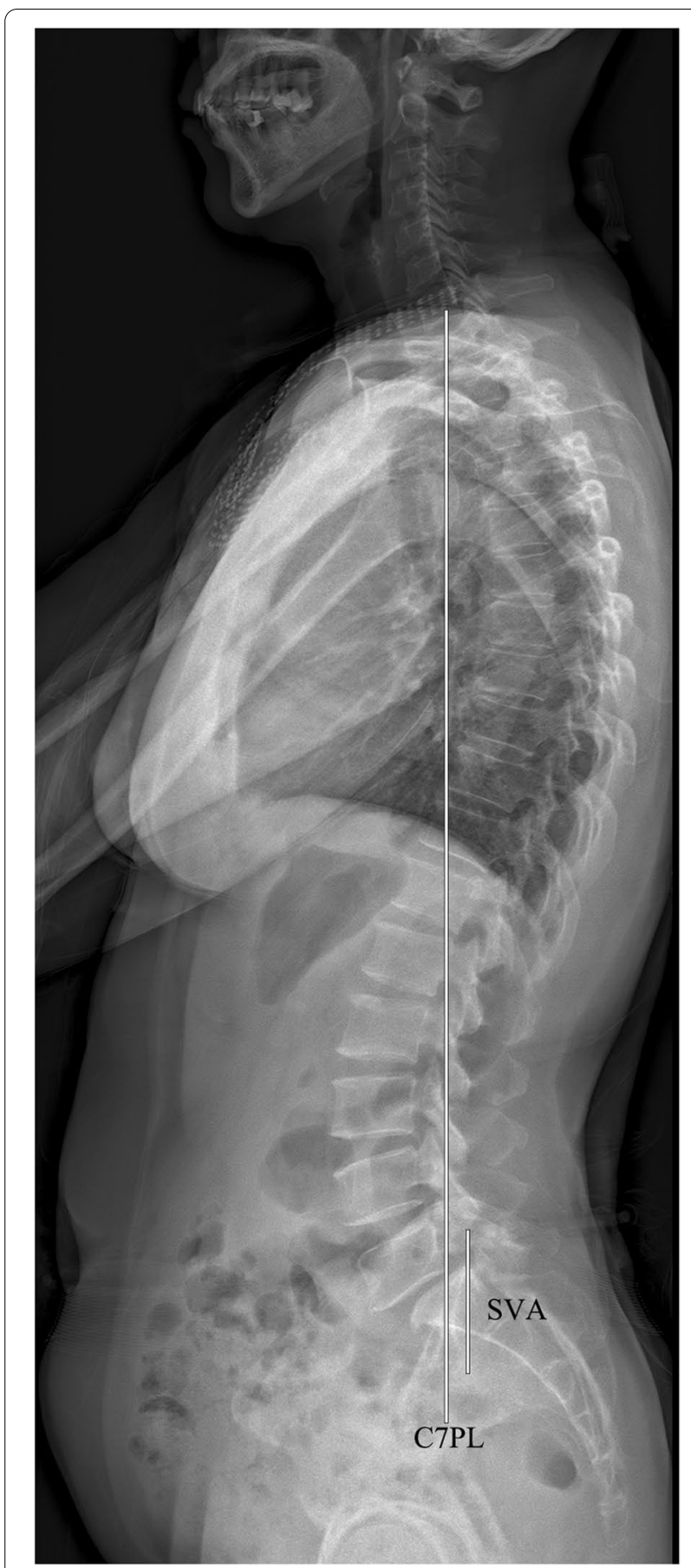

Fig. 5 The radiological SVA measurement

$P<0.05)$. At the final follow-up, the $6 \mathrm{~S}$ group exhibited better correction in LL, SL, and PT, compared to the $4 \mathrm{~S}$ group (all $P<0.05$ ). Additionally, the SD improvement was significantly better in the $6 \mathrm{~S}$ group, compared to the $4 \mathrm{~S}$ group at all points after surgery $(P<0.05)$. Likewise, the slip correction rate was significantly larger after
Table 1 Demographic data of patients in the two groups

\begin{tabular}{llll}
\hline & 4S group & 6S group & P value \\
\hline Number & 37 & 39 & \\
Gender(male/female) & $10 / 27$ & $14 / 25$ & 0.405 \\
Age (years) & $55.2 \pm 10.8$ & $58.1 \pm 7.5$ & 0.176 \\
BMI (kg/m2) & $24.73 \pm 2.94$ & $25.14 \pm 3.79$ & 0.601 \\
BMD(T-score) & $-1.95 \pm 1.05$ & $-2.01 \pm 0.79$ & 0.778 \\
Meyerding grade & $I^{\circ}(n=24)$ & $I^{\circ}(n=24)$ & 0.764 \\
& $\|^{\circ}(n=13)$ & $\|^{\circ}(n=15)$ & \\
SVA (\%) & & & \\
$\quad$ & & & \\
$\quad$ cm but $\leq 5 \mathrm{~cm}$ & $67.6 \%(n=25)$ & $64.1 \%(n=25)$ & 0.750 \\
Follow-up (months)) & $32.4 \%(n=12)$ & $35.9 \%(n=14)$ & \\
Operative time (min) & $16.95 \pm 4.16$ & $17.33 \pm 3.81$ & 0.679 \\
Blood loss (ml) & $166.76 \pm 57.54$ & $214.87 \pm 75.67$ & $\mathbf{0 . 0 0 3}$ \\
Total cost (USD) & $10,670 \pm 1658$ & $12,054 \pm 1967$ & $\mathbf{0 . 0 2 8}$ \\
\hline
\end{tabular}

$B M I$ Body mass index, BMD Bone mineral density, SVA Sagittal vertical axis Bold represents there is statistical significance between the groups, $p<0.05$

surgery in the $6 \mathrm{~S}$ group versus $4 \mathrm{~S}$ group $(P<0.05)$. No significant preoperative differences were observed in all parameters between the two groups. All radiographic outcomes are summarized in Table 2.

\section{Clinical functional outcomes}

In both groups, compared to the preoperative values, the VAS and ODI scores showed significant differences at all points after surgery (all $P<0.05$ ). The preoperative VAS and ODI scores in both groups were similar (all $P<0.05$ ) and no significant differences were seen in the VAS and ODI scores in both groups at all time points after surgery. All the clinical outcomes are summarized in Table 3.

\section{Discussion}

The slipped vertebra reduction remains a controversial issue in the surgical treatment of lumbar spondylolisthesis. In 2011, Audat et al. [5] reported that spondylolisthesis reduction is unnecessary as the clinical outcomes remain the same with or without reduction. However, other studies confirmed marked decreases in SD. Sears et al. [6] reported a good clinical outcome in $83 \%$ of cases after slip reduction of spondylolisthesis. In a prospective study involving 40 patients with degenerative spondylolisthesis, Wegmann et al. [7] demonstrated that reduction strongly correlates with improvements in quality-of-life scores (QLS). Spondylolisthesis reduction can, therefore, restore spinal canal volume, correct tapering of the nerve root hole, protect nerve roots from being pulled, and regain the overall physical arrangement of the vertebral body. In addition, decrease in SD may have a positive effect on LL correction. Kawakami et al. 
Table 2 Comparison of radiographic parameters between the two groups

\begin{tabular}{|c|c|c|c|}
\hline & $4 \mathrm{~S}$ group & $6 \mathrm{~S}$ group & $P$ value \\
\hline \multicolumn{4}{|l|}{$\operatorname{LL}\left({ }^{\circ}\right)$} \\
\hline Pre & $52.30 \pm 7.94$ & $53.02 \pm 8.55$ & 0.705 \\
\hline 1 month & $57.49 \pm 6.51^{*}$ & $60.17 \pm 7.10^{*}$ & 0.090 \\
\hline 6 months & $57.30 \pm 6.45^{*}$ & $60.08 \pm 7.06^{*}$ & 0.077 \\
\hline Final & $56.35 \pm 6.15^{*}$ & $59.55 \pm 6.84^{*}$ & 0.036 \\
\hline \multicolumn{4}{|l|}{$S L\left(^{\circ}\right)$} \\
\hline pre & $16.32 \pm 4.83$ & $16.04 \pm 4.54$ & 0.999 \\
\hline 1 month & $24.37 \pm 2.68^{*}$ & $25.21 \pm 2.95^{*}$ & 0.197 \\
\hline 6 months & $24.26 \pm 2.60^{*}$ & $25.16 \pm 2.91^{*}$ & 0.160 \\
\hline Final & $23.49 \pm 2.34^{*}$ & $24.88 \pm 2.85^{*}$ & 0.023 \\
\hline \multicolumn{4}{|l|}{$\mathrm{PI}\left(\left(^{\circ}\right)\right.$} \\
\hline Pre & $61.84 \pm 9.35$ & $62.64 \pm 10.03$ & 0.721 \\
\hline 1 month & $62.30 \pm 9.02$ & $62.44 \pm 9.83$ & 0.949 \\
\hline 6 months & $62.35 \pm 9.07$ & $62.33 \pm 9.91$ & 0.992 \\
\hline Final & $62.22 \pm 9.04$ & $62.41 \pm 9.86$ & 0.931 \\
\hline \multicolumn{4}{|l|}{ PT $\left({ }^{\circ}\right)$} \\
\hline Pre & $21.27 \pm 4.00$ & $20.85 \pm 5.05$ & 0.690 \\
\hline 1 month & $16.41 \pm 4.23^{*}$ & $15.03 \pm 4.27^{*}$ & 0.161 \\
\hline 6 months & $16.62 \pm 4.04^{*}$ & $15.21 \pm 4.11^{*}$ & 0.136 \\
\hline Final & $17.35 \pm 3.98^{*}$ & $15.49 \pm 4.05^{*}$ & 0.047 \\
\hline \multicolumn{4}{|l|}{ SS $\left(^{\circ}\right)$} \\
\hline Pre & $40.76 \pm 10.19$ & $41.87 \pm 10.18$ & 0.532 \\
\hline 1 month & $46.51 \pm 9.71^{*}$ & $47.46 \pm 10.37^{*}$ & 0.681 \\
\hline 6 months & $46.11 \pm 9.48^{*}$ & $47.15 \pm 10.35^{*}$ & 0.650 \\
\hline Final & $45.27 \pm 9.26^{*}$ & $46.85 \pm 10.34^{*}$ & 0.486 \\
\hline \multicolumn{4}{|l|}{ SVA (mm) } \\
\hline Pre & $54.43 \pm 46.21$ & $56.52 \pm 45.76$ & 0.844 \\
\hline 1 month & $31.26 \pm 43.78^{*}$ & $27.81 \pm 42.98^{*}$ & 0.730 \\
\hline 6 months & $32.98 \pm 43.85^{*}$ & $28.01 \pm 43.07^{*}$ & 0.620 \\
\hline Final & $33.71 \pm 44.64^{*}$ & $28.98 \pm 44.12^{*}$ & 0.644 \\
\hline \multicolumn{4}{|l|}{ SD (\%) } \\
\hline Pre & $22.40 \pm 7.20$ & $23.18 \pm 7.53$ & 0.646 \\
\hline 1 month & $6.67 \pm 2.88^{*}$ & $5.23 \pm 2.12^{*}$ & 0.015 \\
\hline 6 months & $7.03 \pm 2.54^{*}$ & $5.59 \pm 1.89^{*}$ & 0.009 \\
\hline Final & $8.08 \pm 2.53^{*}$ & $6.08 \pm 2.07^{*}$ & 0.003 \\
\hline Slip correction rate (\%) & $68.86 \pm 15.67$ & $77.25 \pm 7.4$ & 0.004 \\
\hline
\end{tabular}

LL Lumbar lordosis, SL Segmental lordosis, PI Pelvic incidence, PT Pelvic tilt, SS Sacral slope, SD Slippage degree, SVA Sagittal vertical axis

Slip correction rate $(\%)=[($ preoperative slip percentage - postoperative slip percentage)/(preoperative slip percentage) $\times 100 \%]$

1 month: one month after surgery, 6 months: six months after surgery, FINAL: final follow-up

*Statistically significant compared with the preoperative value, $p<0.05$

Bold represents there is statistical significance between the groups, $p<0.05$

[8] reported that a decrease in SD was highly associated with enhanced LL correction. If the SD reduction of the slipped vertebra in lumbar spondylolisthesis is successful, compressive techniques with posterior instrumentation
Table 3 Comparison of functional outcomes between the two groups

\begin{tabular}{llll}
\hline & 4S group & 6S group & P value \\
\hline VAS & & & \\
Pre & $7.62 \pm 1.28$ & $7.46 \pm 1.05$ & 0.552 \\
1 month & $3.24 \pm 0.72^{*}$ & $3.56 \pm 0.75^{*}$ & 0.062 \\
6 months & $2.46 \pm 0.73^{*}$ & $2.38 \pm 0.88^{*}$ & 0.668 \\
Final & $1.65 \pm 0.68^{*}$ & $1.54 \pm 0.60^{*}$ & 0.456 \\
ODI & & & \\
Pre & $54.32 \pm 9.55$ & $55.64 \pm 10.50$ & 0.569 \\
1 month & $26.81 \pm 5.88^{*}$ & $27.41 \pm 5.96^{*}$ & 0.660 \\
6 months & $20.65 \pm 3.43^{*}$ & $19.08 \pm 4.49^{*}$ & 0.092 \\
Final & $18.86 \pm 4.77^{*}$ & $18.23 \pm 4.15^{*}$ & 0.540 \\
Chronic low back pain & 2 & 1 & 0.525 \\
\hline
\end{tabular}

VAS Visual analogue scale, ODI Oswestry Disability Index, CLBP Chronic low back pain

1 month: one month after surgery, 6 months: six months after surgery, FINAL: final follow-up

*Statistically significant compared with the preoperative value, $p<0.05$

Bold represents there is statistical significance between the groups, $p<0.05$

can be readily performed. There is no technical difficulty in treating lumbar spondylolisthesis with an additional screw in the proximal vertebral body. In fact, the upper screws can serve as a leverage point and the upper and lower displaced vertebral bodies can act as anchors to facilitate a middle bridge-shaped pulling reduction, under direct vision. Adding a screw to the proximal vertebral body produces a stronger lifting force, a more uniform stress distribution, and an enhanced secure reduction effect. The risk of pedicle screw extraction can also be reduced, particularly in patients with osteoporosis. In this study, SD was significantly decreased in the $6 \mathrm{~S}$ group, compared to the $4 \mathrm{~S}$ group at all points after surgery. This indicated that SD was significantly decreased by introducing the additional upper pedicle screws in PLIF surgery. Hence, patients in the $6 \mathrm{~S}$ group, relative to the $4 S$ group, received sufficient distraction reduction.

Lumbar spondylolisthesis almost always occurs in the lumbosacral segment, which is similar to the thoracolumbar segment, owing to its unique anatomical and biomechanical features. Prior studies reported $[9,10]$ that about $70 \%$ of the global LL are located in the last two lumbar levels. During lumbar spinal fusion surgery, LL recovery is a priority. However, it is difficult to mediate, especially, in terms of the acquisition of total LL during surgery. Takahashi et al. [11] reported that an increased SL in turn increases LL. Therefore, SL acquisition leads to LL. In this study, the postoperative LL and SL of both groups were significantly improved, compared to before surgery. After PLIF surgery, no significant differences were observed in LL and SL values 
between the two groups, but the LL and SL values in the $6 \mathrm{~S}$ group were better maintained at the last followup. We speculate that this is due to the varying fixation methods used during surgery. The 6 screws in 3 vertebrae were obviously more superior to the 4 screws in 2 vertebrae, particularly, in terms of fixation strength and stress distribution, in the fixation mode of lumbar spondylolisthesis.

The sagittal sacropelvic morphology and orientation intercede lumbar spinal geometry. In case of abnormal sacropelvic morphology and orientation, a disturbed global sagittal spinal balance is achieved. PI is a fixed parameter that is independent of pelvis orientation. PI is equal to the arithmetic sum of SS and PT [12] . The standard PI value is approximately $53^{\circ} \pm 9^{\circ}$ [13]. In this study, PI was significantly higher, compared to the standard value, which is coincident with other publications [14]. There was also a close relationship between PI and LL (the ideal relationship is: $\mathrm{LL}=\mathrm{PI} \pm 9^{\circ}$ [15]. Patients with a high PI value require more extended LL after surgery in order to maintain sagittal balance. PT and SS, on the other hand, are positional and are related to pelvic orientation. The standard PT value is approximately $13 \pm 6^{\circ}$ [16]. Kim et al. [17] reported that PT has a strong correlation with good clinical outcomes. Additionally, PT improvement after PLIF surgery may be one of the reasons for low back pain relief in patients with lumbar spondylolisthesis. In this study, we showed no statistically significant differences in PI and SS values between the two groups. Although there was significant difference between the two groups in PT values at the last follow-up, the difference was small. Therefore, it appears that short and long segment pedicle screw fixations do not massively influence the spinopelvic sagittal plane after surgery. However, the postoperative patients in this study lacked in performing daily activities, mostly due to old age. Meanwhile, the follow-up time was short, and could not accurately reflect the effect of screw numbers on spinal-pelvic sagittal balance.

Compared to the preoperative status in this study, VAS and ODI values decreased significantly after surgery in both groups. Although most patients reported satisfied clinical functional improvement after surgery, three patients in both groups suffered from chronic low back pain. Rajnics et al. [18] reported that failed restoration of LL may cause chronic low back pain post surgery. This is likely due to the painful compensation with hyperextension at the upper adjacent levels, due to the increase in traction load on the posterior spinal arrangement. LL restoration did not change, and even worsened, in these three patients with chronic low back pain in our study.
Lee et al. [19] reported that the incidence of adjacent segment disease (ASD) is markedly higher after PLIF surgery. This is because the spinal fixation instruments and fusion cage can significantly increase segment stiffness and stress transmission to the adjacent segment, thus accelerating the postoperative degeneration process of the adjacent segment. Similarly, some scholars speculate that long segment fixation will promote normal segment degeneration, since the longer lever arm from the multi-segment fusion will generate more stress on the remaining free segment [20]. Gene et al. [21] advocated the new-onset substantial mechanical back pain as a possible symptom of ASD. However, Kumar et al. [22] reported that longer level fusions or a PLIF addition does not increase ASD risk. Till date, studies have not definitively revealed whether the radiological alterations and clinical deterioration of ASD are the result of spinal fusion or iatrogenic production of a rigid motion segment. The exact mechanism of ASD is uncertain, but some risk factors, such as, pre-existing degeneration of the adjacent segment, exert a negative impact on ASD. Moreover, secondary degeneration of the proximal segment of spondylolisthesis may occur due to alterations in the normal spinal sequence after lumbar spondylolisthesis. Lee et al. [23] reported that pre-existing disc degeneration increases biomechanical changes in adjacent segment after surgery. Some surgeons might perform a complete PLIF at the adjacent level. However, Zhang et al. [24] demonstrated that a distraction of the intervertebral space and facet fusions in the adjacent segment can effectively prevent ASD. During PLIF surgery, bone graft fusion is generally performed to correct spondylolisthesis. However, in this study, the normal segment was only fixed without fusion in the $6 \mathrm{~S}$ group, which achieved augmented LL and SL, compared to the $4 \mathrm{~S}$ group. In terms of longer segmental fixation, such as, L1-S1 fixation, the L4-S1 fixation is known to avoid the complete loss of lumbar activity, induce less surgical trauma, and reduce the cost of internal fixation. Therefore, in this study, two segment fixation was recommended for patients with isthmic L5-S1 spondylolisthesis, with a long course of disease, degeneration of adjacent segments, and low bone density.

There were certain limitations in our study. Firstly, this was a retrospective study. Hence, our nonrandomized design may have unintentionally introduced selection bias. Secondly, our patient population was relatively small. Finally, the mean follow-up time was relatively short (less than 2 years). In future investigations, we recommend conducting prospective multicenter studies, involving large patient population, and long-term follow up. 


\section{Conclusion}

We employed two approaches to examine the post-surgical lumbar spinal sagittal stabilities and clinical functional outcomes of lumbar spondylolisthesis patients. Based on our analysis, both $4 \mathrm{~S}$ and $6 \mathrm{~S}$ markedly these parameters after surgery. However, relative to the $4 \mathrm{~S}$ group, the $6 \mathrm{~S}$ group exhibited a greater advantage in restoration and maintenance of radiographic parameters.

\section{Abbreviations}

PLIF: Posterior lumbar interbody fusion; BMD: Bone mineral density; BMI: Body mass index; LL: Lumbar lordosis; SL: Segmental lordosis; PI: Pelvic incidence; PT: Pelvic tilt; SS: Sacral slope; SD: Slippage degree; SVA: Sagittal vertical axis; CLBP: Chronic low back pain; VAS: Visual analogue scales; ODI: Oswestry Disability Index.

\section{Acknowledgements}

The present study was supported by The First Affiliated Hospital of Soochow University.

\section{Authors' contributions}

XFS, HL, WJ contributed to draft the manuscript text. RQ and TL designed the concept, ZLQ revised the manuscript. All authors read and approved the final manuscript.

\section{Funding}

This study was supported by National Natural Science Foundation of China (82072476), Natural Science Foundation of Jiangsu Province (BK20191173), Youth Science and technology project of rejuvenating health through science and education in Suzhou (KJXW2019010), Science and Technology Project of Ili Kazakh Préfecture Autonome (YZ2019D004), Bethune special fund for strengthening treatment of pathological spinal fracture (BK-JP201702).

\section{Availability of data and materials}

The datasets used and/or analyzed during the current study available from the corresponding author on reasonable request.

\section{Declarations}

\section{Ethics approval and consent to participate}

Ethical approval from the Medical Ethics Committee of the First Affiliated Hospital of Soochow University was obtained for this study. All methods were carried out in accordance with the relevant guidelines and regulations. Written informed consent was obtained from all participants.

\section{Consent for publication}

Not applicable.

\section{Competing interests}

The authors declare that there is no conflict of interest.

\section{Author details}

${ }^{1}$ Department of Orthopedic Surgery, The First Affiliated Hospital of Soochow University, No. 188 Shizi Street, Suzhou, Jiangsu 215006, P.R. China. ${ }^{2}$ The Department of Orthopedic Surgery, Changsu No.2. People's Hospital, Jiangsu, Suzhou, China. ${ }^{3}$ Department of Orthopedic Surgery, The Affiliated Suzhou Hospital of Nanjing Medical University, No. 26 Daoqian Street, Suzhou, Jiangsu 215006, P.R. China.

Received: 19 October 2021 Accepted: 9 February 2022

Published online: 12 February 2022

\section{References}

1. Sclafani JA, Constantin A, Ho PS, Akuthota V, Chan L. Descriptive analysis of spinal Neuroaxial injections, surgical interventions, and physical therapy utilization for degenerative lumbar spondylolisthesis within Medicare beneficiaries from 2000 to 2011. Spine (Phila Pa 1976). 2017:42(4):240-6.

2. Cloward RB. Posterior lumbar interbody fusion updated. Clin Orthop Relat Res. 1985:193:16-9.

3. Li Y, Wu Z, Guo D, You H, Fan X. A comprehensive comparison of posterior lumbar interbody fusion versus posterolateral fusion for the treatment of isthmic and degenerative spondylolisthesis: a meta-analysis of prospective studies. Clin Neurol Neurosurg. 2020;188:105594.

4. Feng Y, Chen L, Gu Y, Zhang ZM, Yang HL, Tang TS. Restoration of the spinopelvic sagittal balance in isthmic spondylolisthesis: posterior lumbar interbody fusion may be better than posterolateral fusion. Spine J. 2015:15(7):1527-35.

5. Audat ZM, Darwish FT, Al Barbarawi MM, Obaidat MM, Haddad WH, Bashaireh KM, et al. Surgical management of low grade isthmic spondylolisthesis; a randomized controlled study of the surgical fixation with and without reduction. Scoliosis. 2011;6(1):14.

6. Sears W. Posterior lumbar interbody fusion for degenerative spondylolisthesis: restoration of sagittal balance using insert-and-rotate interbody spacers. Spine J. 2005;5(2):170-9.

7. Wegmann K, Gundermann S, Siewe J, Eysel P, Delank KS, Sobottke R. Correlation of reduction and clinical outcome in patients with degenerative spondylolisthesis. Arch Orthop Trauma Surg. 2013;133(12):1639-44.

8. Kawakami M, Tamaki T, Ando M, Yamada H, Hashizume H, Yoshida M. Lumbar sagittal balance influences the clinical outcome after decompression and posterolateral spinal fusion for degenerative lumbar spondylolisthesis. Spine (Phila Pa 1976). 2002;27(1):59-64.

9. Jackson RP, McManus AC. Radiographic analysis of sagittal plane alignment and balance in standing volunteers and patients with low back pain matched for age, sex, and size. Spine (Phila Pa 1976). 1994;19(14):1611-8.

10. Roussouly P, Pinheiro-Franco JL. Sagittal parameters of the spine: biomechanical approach. Eur Spine J. 2011;20(Suppl 5):578-85.

11. Takahashi Y, Okuda S, Nagamoto Y, Matsumoto T, Sugiura T, Iwasaki M. Effect of segmental lordosis on the clinical outcomes of 2-level posterior lumbar interbody fusion for 2-level degenerative lumbar spondylolisthesis [published online ahead of print, 2019 Jul 12]. J Neurosurg Spine. 2019;1-6.

12. Duval-Beaupere G, Schmidt C, Cosson P. A Barycentremetric study of the sagittal shape of spine and pelvis: the conditions required for an economic standing position. Ann Biomed Eng. 1992;20(4):451-62.

13. Boulay C, Tardieu C, Hecquet J, Benaim C, Mouilleseaux B, Marty C, et al. Sagittal alignment of spine and pelvis regulated by pelvic incidence: standard values and prediction of lordosis. Eur Spine J. 2006;15(4):415-22.

14. Hanson DS, Bridwell KH, Rhee JM, Lenke LG. Correlation of pelvic incidence with low- and high-grade isthmic spondylolisthesis. Spine (Phila Pa 1976). 2002;27(18):2026-9.

15. Schwab F, Lafage V, Patel A, Farcy JP. Sagittal plane considerations and the pelvis in the adult patient. Spine (Phila Pa 1976). 2009;34(17):1828-33.

16. Greimel F, Wolkerstorfer S, Sporrer JF, Zeman F, Hoffstetter P, Grifka J, et al. Radiological outcome of postoperative sagittal balance on standing radiographs in comparison to intraoperative radiographs in prone position when performing lumbar spinal fusion. Arch Orthop Trauma Surg. 2017;137(10):1319-25.

17. Kim MK, Lee SH, Kim ES, Eoh W, Chung SS, Lee CS. The impact of sagittal balance on clinical results after posterior interbody fusion for patients with degenerative spondylolisthesis: a pilot study. BMC Musculoskelet Disord. 2011:12:69.

18. Rajnics P, Templier A, Skalli W, Lavaste F, Illes T. The association of sagittal spinal and pelvic parameters in asymptomatic persons and patients with isthmic spondylolisthesis. J Spinal Disord Tech. 2002;15(1):24-30.

19. Lee JC, Kim Y, Soh JW, Shin BJ. Risk factors of adjacent segment disease requiring surgery after lumbar spinal fusion: comparison of posterior lumbar interbody fusion and posterolateral fusion. Spine (Phila Pa 1976). 2014;39(5):E339-45.

20. Schulte TL, Leistra F, Bullmann V, Osada N, Vieth V, Marquardt B, et al. Disc height reduction in adjacent segments and clinical outcome 10 years after lumbar 360 degrees fusion. Eur Spine J. 2007;16(12):2152-8.

21. Cheh G, Bridwell KH, Lenke LG, Buchowski JM, Daubs MD, Kim Y, et al. Adjacent segment disease followinglumbar/thoracolumbar fusion with 
pedicle screw instrumentation: a minimum 5-year follow-up. Spine (Phila Pa 1976). 2007;32(20):2253-7.

22. Kumar MN, Jacquot F, Hall H. Long-term follow-up of functional outcomes and radiographic changes at adjacent levels following lumbar spine fusion for degenerative disc disease. Eur Spine J. 2001;10(4):309-13.

23. Lee CS, Hwang CJ, Lee SW, Ahn YJ, Kim YT, Lee DH, et al. Risk factors for adjacent segment disease after lumbar fusion. Eur Spine J. 2009;18(11):1637-43.

24. Zhang X, Zhu J, Li Y, Hao D, Gao W. A modified method to treat severe asymptomatic pre-existing degeneration of adjacent segment: a retrospective case-control study. BMC Surg. 2021;21(1):161.

\section{Publisher's Note}

Springer Nature remains neutral with regard to jurisdictional claims in published maps and institutional affiliations.

- fast, convenient online submission

- thorough peer review by experienced researchers in your field

- rapid publication on acceptance

- support for research data, including large and complex data types

- gold Open Access which fosters wider collaboration and increased citations

- maximum visibility for your research: over $100 \mathrm{M}$ website views per year

At BMC, research is always in progress.

Learn more biomedcentral.com/submissions 